\title{
IS THE NUMBER OF MICROEMBOLIC SIGNALS RELATED TO NEUROLOGIC OUTCOME IN CORONARY BYPASS SURGERY?
}

\author{
Suzana M. F. Malheiros, Ayrton R. Massaro, Alberto A. Gabbai, Clodualdo J. N. Pessa, \\ Luis R. Gerola, João N. R. Branco, Edgar B. Lira Filho, Dejaldo M. J. Christofalo, \\ Darwin Federico, Antonio C. Carvalho, Enio Buffolo
}

\begin{abstract}
Coronary artery bypass surgery (CABG) without cardiopulmonary bypass (CPB) may potentially reduce the number of microembolic signals (MES) associated with aortic manipulation or generated by the pump circuit, resulting in a better neurologic outcome after surgery. Our aim was to compare the frequency of MES and neurologic complications in CABG with and without CPB. Twenty patients eligible to routine CABG without CPB were randomized to surgery with $\mathrm{CPB}$ and without $\mathrm{CPB}$ and continuously monitored by transcranial Doppler. Neurologic examination was performed in all patients before and after surgery. The two groups were similar with respect to demographics, risk factors, grade of aortic atheromatous disease and number of grafts. The frequency of MES in the nonCPB group was considerably lower than in CPB patients, however, we did not observe any change in the neurologic examination during the early postoperative period. Neurologic complications after CABG may be related to the size and composition of MES rather than to their absolute numbers. A large prospective multicentric randomized trial may help to elucidate this complex issue.
\end{abstract}

KEY WORDS: coronary artery bypass, transcranial Doppler, postoperative complications, cardiopulmonary bypass, treatment outcome.

\begin{abstract}
Existe relação entre o número de microêmbolos e a evolução neurológica nas cirurgias de revascularização miocárdica?

RESUMO - A cirurgia de revascularização miocárdica sem circulação extracorpórea (CEC) pode estar relacionada com uma potencial redução no número dos microêmbolos (ME) associados com a manipulação da aorta ou gerados pelo equipamento, com consequente redução do risco de complicações neurológicas nestes pacientes. Nosso objetivo foi comparar a frequência de ME e de complicações neurológicas em pacientes operados sem e com CEC. Vinte pacientes selecionados para revascularização miocárdica eletiva sem CEC foram randomizados para cirurgia com e sem CEC. A monitorização contínua com Doppler transcraniano foi realizada durante todo o procedimento nos dois grupos e os pacientes foram examinados antes e após a cirurgia. Os grupos não apresentaram diferenças significativas em relação aos aspectos demográficos, fatores de risco, grau de ateromatose de aorta e número de pontes realizadas. A frequência de ME no grupo operado sem CEC foi significativamente menor do que no grupo operado com CEC, entretanto, nenhum paciente apresentou alterações no exame neurológico no período pós-operatório inicial. Esta observação pode sugerir que as complicações neurológicas possam estar mais relacionadas com o tamanho e a composição, do que com o número de ME. Somente um estudo prospectivo com maior número de pacientes poderá esclarecer este assunto.
\end{abstract}

PALAVRAS-CHAVE: revascularização miocárdica, ponte de artéria coronária, complicações pós-operatórias, Doppler transcraniano, circulação extracorpórea.

Neurologic complications remain important cause of morbidity in coronary artery bypass grafting $(C A B G)^{1}$ despite improvements in surgical techniques and cardiopulmonary bypass (CPB) equipments.
Cerebral hypoperfusion as well as microembolism associated with CPB are the main postulated mechanisms of brain injury in these patients ${ }^{2,3}$.

Microembolic signals (MES) detected by transcra-

From the Departments of Neurology, Cardiovascular Surgery, Cardiology, Radiology and Anesthesiology of Universidade Federal de São Paulo and Universidade de São Paulo, São Paulo SP, Brazil. This study was supported by FAPESP (Fundação de Amparo à Pesquisa do Estado de São Paulo)

Received 5 October 2000, receive in final form 16 October 2000. Accepted 28 November 2000.

Suzana M. F. Malheiros, MD - Department of Neurology, Escola Paulista de Medicina, Universidade Federal de São Paulo, Rua Botucatu 740 - 04023-900 São Paulo SP - Brasil. Fax: 55113023 3051. E-mail: suzana@sun-nepi.epm.br 
nial Doppler (TCD) have been described in virtually all patients undergoing conventional CABG with CPB and are thought to be predominantly related to aortic manipulation, including aortic cannulation, cross-clamping and declamping ${ }^{4,5}$. However, not all MES observed during CPB can be directly associated with surgical manipulations and a large proportion of them probably represents air bubbles or microparticulate emboli generated from the pump circuit and not completely eliminated by the arterial line filters ${ }^{4-7}$.

We have previously described the absence of MES detection by TCD in 2 patients undergoing CABG without $\mathrm{CPB}^{8}$ and hypothesized that this technique might reduce the number of emboli related to aortic manipulation as well as microemboli associated with the CPB circuit.

Our aim was to evaluate the frequency of MES and its relation to neurologic complications in patients randomized to CABG with and without CPB.

\section{METHOD}

The protocol was approved by our institutional review board. After written informed consent, 20 patients eligible to routine $C A B G$ without $C P B$ were randomized to either CABG with $C P B$ (CPB group) or without CPB (nonCPB group). Patient selection for $C A B G$ without $C P B$ was based exclusively in technical aspects: patients with diagonal, left anterior descending artery (LAD) and right coronary artery lesions were eligible to this technique'.

Exclusion criteria included reoperation, concomitant surgical procedures, renal or pulmonary failure, carotid stenosis $>70 \%$ and significantly impaired ventricular function.

All patients were subjected to a detailed preoperative neurologic examination, Doppler ultrasound to assess carotid stenosis and transesophageal echocardiography to evaluate the presence of aortic atheroma ${ }^{10}$. After surgery, all patients were reexamined by the same neurologist (S.M.F.M.) at the immediate postoperative period (within the first 24 hours) and before discharge, to detect any change, even minor, when compared to the preoperative neurologic examination. All surgeries were performed by the same team.

\section{Anesthesia}

Both groups received the same anesthetic regimen. After induction with midazolam, etomidate, fentanyl and pancuronium, anesthesia was maintained with fentanyl and isoflurane.

\section{Cardiopulmonary bypass}

Our protocol included moderate hypothermia $\left(28^{\circ} \mathrm{C}\right)$, non-pulsatile flow, membrane oxygenators, arterial line filter and alpha-stat control of acid-base management.

\section{TCD monitoring ${ }^{11}$}

Patients were continuously monitored by the same neurologist (A.R.M.) with a TCD system (EME-Companion) using a 2-MHz probe (depth of 4.5-6.0 cm, sample volume 5-10 mm, $128 \mathrm{FFT}$, sweep time 3.1 seconds) from the induction of general anesthesia to the end of the surgical procedure. Right middle cerebral artery was monitored in all patients. MES were defined as typical visible and audible short duration, high intensity signals. MES detection was based on both of the following criteria: (1) listening to the signal through a headphone during online visual observation; and (2) an automated software for MES detection with a threshold of $12-d B$, to improve reproducibility and specificity.

\section{Statistical analysis}

Statistical analysis was performed with the SPSS (version 8.0) and StatView (version 5.0.1). Demographics, risk factors and surgical parameters (surgery duration and number of grafts and MES) were compared for the two groups individually using Student's $t$ test for continuous variables and Fisher's exact test for categorical variables.

Table 1. Demographics and risk factors including aortic atheroma grade in the two groups.

\begin{tabular}{lccc}
\hline & nonCPB $\mathrm{n}=12$ & $\mathrm{CPB} \mathrm{n}=8$ & $\mathrm{P}^{1}$ \\
\hline $\begin{array}{l}\text { demographics } \\
\text { mean age, years (SD) }\end{array}$ & $62.1(8.4)$ & $58.2(8.6)$ & $0.33^{*}$ \\
male & $6(50 \%)$ & $5(62 \%)$ & 0.67 \\
risk factors & & & \\
arterial hypertension & $8(67 \%)$ & $6(75 \%)$ & 1.00 \\
diabetes & $2(17 \%)$ & $2(25 \%)$ & 1.00 \\
hypercholesterolemia & $4(33 \%)$ & $5(62 \%)$ & 0.36 \\
smoking & $10(83 \%)$ & $7(88 \%)$ & 1.00 \\
previous myocardial infarction & $7(58 \%)$ & $3(38 \%)$ & 0.65 \\
previous stroke or TIA & $1(8 \%)$ & $1(12 \%)$ & 1.00 \\
\hline
\end{tabular}

$p^{1}$ Fisher's exact test except where indicated. * Student's $t$ test. SD, standard deviation; CPB, with cardiopulmonary bypass; nonCPB, without cardiopulmonary bypass; TIA, transient ischemic attack. 
Table 2. Mean number of MES ( $\pm S D$ ) according to the numbers of grafts in the two groups.

\begin{tabular}{ccc}
\hline & \multicolumn{2}{c}{ MES (mean \pm SD) } \\
$\begin{array}{c}\text { number } \\
\text { of grafts }\end{array}$ & nonCPB & \\
\hline 1 & 0 & $748.3 \pm 899$ \\
2 & $4.6 \pm 3.8$ & $566.3 \pm 261.1$ \\
3 & $33 \pm 4.2$ & $2032.5 \pm 826.6$ \\
\hline
\end{tabular}

$\mathrm{SD}$, standard deviation; $\mathrm{CPB}$, with cardiopulmonary bypass; nonCPB, without cardiopulmonary bypass.

To analyze the number of MES we used a logarithmic transformation [LN(0.5+MES)]. For all tests, statistical significance was accepted at $p<0.05$.

\section{RESULTS}

The two groups (nonCPB and CPB) were similar in respect to demographics and risk factors for cerebrovascular diseases as summarized in Table 1.

The grade of aortic atheromatous disease $(p=0.69)$ as well as the number of grafts $(p=0.90)$ did not differ between the two groups. Total surgery duration was significantly longer in the CPB group (mean $239.4 \pm 44.8$ minutes versus $183.7 \pm 53.3$ minutes in the nonCPB group; $p=0.02$ ).

The number of MES was significantly lower in the nonCPB group $(p<0.0001)$ and varied from zero to 36 (mean $7.4 \pm 12.4$ ). Five patients underwent a single graft, internal mammary artery to left anterior descending artery (IMA/LAD), without aortic clamping and no MES have been detected. Five patients with two grafts presented one to 10 MES. Two patients with three grafts presented 30 and 36 MES respectively, particularly during lateral aortic clamping and declamping, none of them during IMA LAD grafting. In the CPB group the mean number of MES was $1001.1 \pm 871.9$. Three patients underwent a single graft (IMA/LAD) and presented 70 to 1768 MES, while three patients with two grafts presented 320 to $539 \mathrm{MES}$ and two patients with three grafts had 1448 and 2617 MES respectively.

Table 2 shows the mean number of MES in the two groups according to the number of grafts. We can notice that in the CPB group the relationship between the number of grafts and MES is not as clear as observed in the nonCPB group.

Although surgery duration was significant longer in the CPB group, it could not be related to the higher numbers of MES observed in this group (Fig 1).

We also observed flow velocity and pulsatility index changes mainly related to arrhythmias, transient systemic hypotension and heart manipulation in most nonCPB patients.

Neurologic examination after surgery and before discharge did not show any change when compared to preoperative examination in all patients.

\section{DISCUSSION}

We confirm herein our previous observation ${ }^{8}$ that the frequency of MES detected by TCD in CABG without $C P B$ was considerably lower than in $C A B G$ with CPB. Even if we consider only patients that

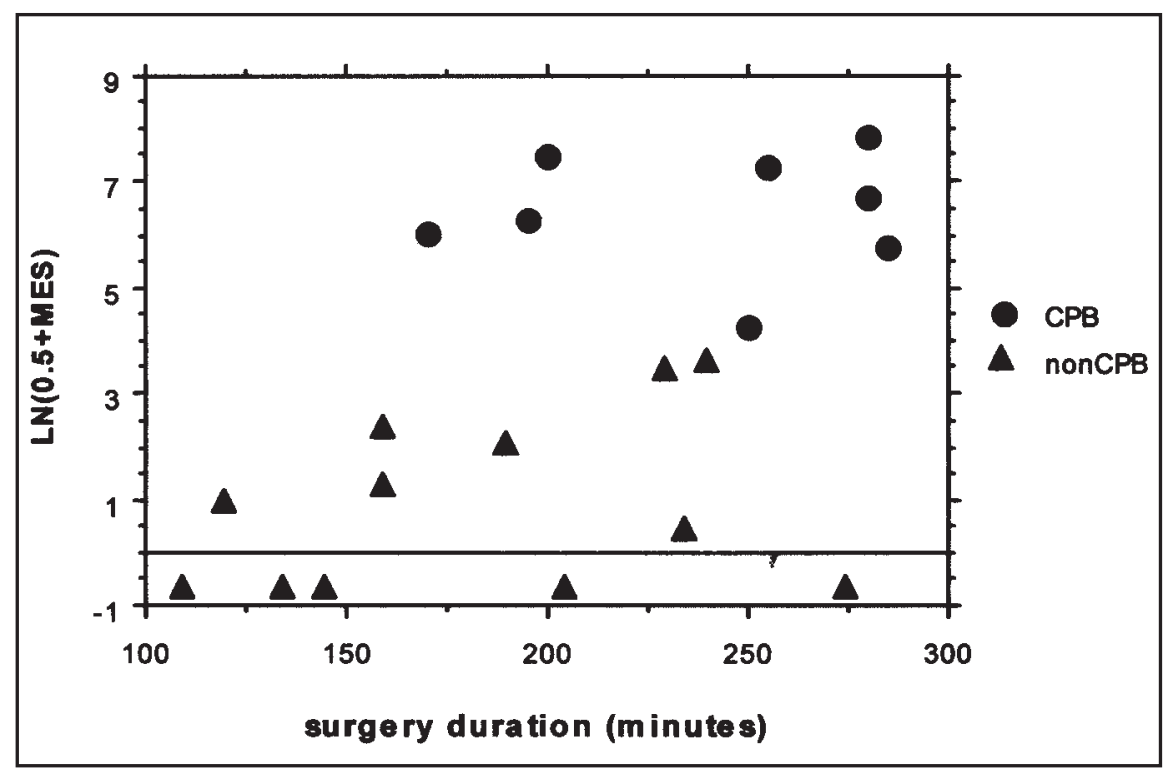

Fig 1. Number of MES (logarithmic transformation) and duration of surgery in patients undergoing $C A B G$ with $C P B$ and without $C P B$. 
underwent a single graft (IMA/LAD) in the CPB group, the frequency of MES was definitely higher when compared to nonCPB patients. Microemboli in nonCPB group seem to be almost exclusively related to aortic manipulation, as suggested by the absence of MES detection in all patients subjected to IMA/ LAD grafts, where no aortic clamping is required. In the CPB group, however, MES probably included gaseous and microparticulate emboli generated by the pump circuit in addition to the microemboli associated with aortic manipulation, as previously described ${ }^{4-7}$. Despite the significant differences in the number of MES between the two groups, no neurologic complication occurred in CPB and nonCPB patients.

Our results confirm recent studies that report a significant difference in MES observed in myocardial revascularization with and without $\mathrm{CPB}^{12-16}$. BhaskerRao and coworkers ${ }^{12}$ compared neurologic outcome in 305 patients undergoing conventional CABG with CPB to 17 patients undergoing minimally invasive bypass surgery. They found a significantly higher number of MES in the CPB group and suggested that this finding is associated with the lower scores in the neuropsychologic examination observed in this group. The two groups, however, were not perfectly comparable, considering that patients were selected for the off-pump procedure based on the presence of severe comorbid illness that prohibited the use of CPB and most of them (59\%) required only a single graft performed by left mini-thoracotomy approach. Diegeler and coworkers ${ }^{13}$ also found a higher number of MES in 20 conventional CABG patients when compared to 20 patients operated without CPB and suggested that the there is a clear association between cerebral microemboli and postoperative impairment in cognitive function. Although they included patients undergoing double or triple-revascularization randomized to surgery with and without CPB, they affirm that off-pump operation was usually applied to patients having isolated coronary artery disease. Murkin and coworkers ${ }^{14}$ also reported part of an ongoing study with a series of 33 patients undergoing conventional CABG compared to a demographically similar group of 35 patients operated without CPB and found a significantly lower incidence in cognitive dysfunction in nonCPB group. They also described a virtual absence of cerebral emboli in the patients operated without $\mathrm{CPB}^{15}$. In the nonCPB group, however, $80 \%$ of patients underwent a single coronary bypass without aortic manipulation or dislocation of the heart in addition to different anesthetic regimens, what may account for their better neurologic outcome ${ }^{15}$. Watters and coworkers ${ }^{16}$ also compared 20 patients undergoing CABG with and without CPB. Although the study was not randomized, they observed a significantly higher number of MES in the CPB group and, according to our findings, they could not detect any neurologic deficit in either group. Demographic features, risk factors and the number of grafts were similar in our two groups and, apart from the number of MES, the only significant difference between them was the duration of surgery. It seems obvious that due to the intrinsic differences between operative techniques, CPB surgery takes longer than nonCPB. Recently Brown and coworkers ${ }^{17}$ reported that the embolic load tended to be associated with longer CPB. Although our sample is small, we could not demonstrate a clear relationship between the surgery duration and numbers of MES in both groups.

Considering the striking difference in the frequency of MES observed in patients undergoing CABG with and without CPB we may question the clinical significance of MES in CABG. Neurologic and neuropsychologic complications in CABG with CPB have been mainly attributed to the number of MES detected by TCD monitoring ${ }^{3,4,12,13,15}$, however, in a previous study we observed no significant differences in early neurologic and neuropsychologic outcome between patients undergoing $C A B G$ with and without $\mathrm{CPB}^{18}$. Some recent reports have confirmed our findings ${ }^{19,20}$ suggesting that other potential mechanisms of cerebral injury in cardiac surgery, such as hypoperfusion and systemic inflammatory response are probably involved ${ }^{2}$. Andrew and coworkers ${ }^{19}$ reported little differences in the incidence of neuropsychologic decline between minimally invasive coronary artery bypass grafting operation and single-graft cardiopulmonary bypass patients. Taggart and coworkers ${ }^{20}$ also found a similar pattern of early cognitive decline with late recovery in patients undergoing conventional $C A B G$ with and without $C P B$ suggesting that the role of $C P B$ as the major cause of postoperative neuropsychologic complications is questionable. They comment that the anesthetic regimen, in addition to nonspecific aspects of the surgery may be contributory factors to the cognitive dysfunction after CABG. Furthermore, Jacobs and coworkers ${ }^{6}$ reported no correlation between the number of MES and cerebral glucose metabolism assessed by positron emission tomography with ${ }^{18} \mathrm{~F}-2$-fluoro-2deoxi-D-glucose (FDG-PET) as well as neuropsychologic function. They hypothesize that cognitive 
changes after cardiac surgery may depend more on the location of the MES related brain damage than on the number of MES. In a recent study, Crawley and coworkers ${ }^{21}$ evaluated the number of MES and the neuropsychologic outcome after carotid endarterectomy (CEA) when compared to percutaneous transluminal angioplasty (PTA). Despite the greater frequency of MES during PTA, they found no difference in the neuropsychologic impairment in the two groups as well as a lack of correlation between the number of emboli and the neuropsychologic test scores. They comment that their results differ from those observed in CABG studies probably due to the higher numbers of MES reported in cardiac surgery, however, the constitution and nature of the emboli as well as the hemodynamic changes of CPB might be other potential mechanisms associated with the neurologic complications. Considering that the frequency of MES detected in our nonCPB group was even lower than the mean numbers reported by Crawley and coworkers ${ }^{21}$ and based on previous clinical studies ${ }^{18-20}$ that did not detect differences in neurologic and neuropsychologic outcome between patients undergoing $C A B G$ with and without $C P B$, we could suppose that the size and composition of MES might be the most important mechanisms associated with neurologic complications after CABG. Although fewer, MES in our nonCPB patients occurred almost exclusively associated with aortic manipulation suggesting that they are predominantly particulate in nature. This finding may explain formerly described neurologic and neuropsychologic dysfunctions after surgery in nonCPB patients ${ }^{18-20}$. Furthermore, changes in flow velocity and pulsatility index observed in our nonCPB patients and confirmed by Murkin and coworkers ${ }^{15}$ are probably another potential mechanism of brain injury in these patients.

Notwithstanding the limitation of our sample size, the difference in the number of MES between the two groups seems convincing. After the advent of angioplasty fewer patients from our CABG population are potentially suitable for myocardial revascularization without CPB what hampers the randomization of large numbers of patients by a single center. Only a large prospective multicentric randomized trial may warrant the appropriate risk stratification ${ }^{15}$ required to elucidate the multifactorial and complex genesis of neurologic complications in coronary bypass surgery.
Acknowledgement - We are grateful to Prof. Alexandre Ryuzo Shinzato for the expert assistance in the statistical analysis.

\section{REFERENCES}

1. Roach GW, Kanchuger M, Mangano CM, et al. Adverse cerebral outcomes after coronary bypass surgery. N Engl J Med 1996;335:18571863.

2. Taylor KM. Brain damage during cardiopulmonary bypass. Ann Thorac Surg 1998;65:S20-26.

3. Pugsley W, Klinger L, Paschalis C, Treasure T, Harrison M, Newman $\mathrm{S}$. The impact of microemboli during cardiopulmonary bypass on neuropsychological functioning. Stroke 1994;25:1393-1399.

4. Clark RE, Brillman J, Davis DA, Lovell MR, Price TRP, Magovern GJ Microemboli during coronary artery bypass grafting. Genesis and effect on outcome. J Thorac Cardiovasc Surg 1995;109:249-258.

5. Barbut D, Yao FS, Hager BA, Kavanaugh P, Trifiletti RR, Gold JP. Comparison of transcranial Doppler ultrasonography and transesophageal echocardiography to monitor emboli during coronary artery bypass surgery. Stroke 1996;27:87-90.

6. Jacobs A, Neveling M, Horst M, et al. Alterations of neuropsychological function and cerebral glucose metabolism after cardiac surgery are not related only to intraoperative microembolic events. Stroke 1998;29:660-667.

7. Taylor RL, Borger MA, Weisel RD, Fedorko L, Feindel CM. Cerebral microemboli during cardiopulmonary bypass: increased emboli during perfusionist interventions. Ann Thorac Surg 1999;68:89-93.

8. Malheiros SMF, Massaro AR, Carvalho AC, et al. Transesophageal echocardiography and transcranial Doppler monitoring in coronary artery surgery without cardiopulmonary bypass: preliminary results. Cerebrovasc Dis 1999;9:358-360.

9. Buffolo E, Andrade JCS, Branco JNR, Teles CA, Aguiar LF, Gomes WJ. Coronary artery bypass grafting without cardiopulmonary bypass. Ann Thorac Surg 1996;61:63-66.

10. Katz ES, Tunick PA, Rusinek H, Ribakove G, Spencer FC, Kronzon I. Protruding aortic atheromas predict stroke in elderly patients undergoing cardiopulmonary bypass: experience with intraoperative transesophageal echocardiography. J Am Coll Cardiol 1992;20:70-77.

11. Ringelstein EB, Droste DW, Babikian VL, et al. Consensus on microembolus detection by TCD. Stroke 1998;29:725-729.

12. BhaskerRao B, VanHimbergen D, Edmonds Jr HL, et al. Evidence for improved cerebral function after minimally invasive bypass surgery. J Card Surg 1998;13:27-31.

13. Diegeler A, Hirsch R, Schneider F, et al. Neuromonitoring and neurocognitive outcome in off-pump versus conventional coronary bypass operation. Ann Thorac Surg 2000;69:1162-1166.

14. Murkin JM, Boyd WD, Ganapathy S, Adams SJ, Peterson RC. Beating heart surgery: why expect less central nervous system morbidity? Ann Thorac Surg 1999;68:1498-1501.

15. Murkin JM, Boyd WD, Ganapathy S. Neurologic complications in coronary surgery without cardiopulmonary bypass - reply. Ann Thorac Surg 2000;69: 1992-1993. [letter-replay]

16. Watters MPR, Cohen AM, Monk CR, Angelini GD, Ryder IG. Reduced cerebral embolic signals in beating heart coronary surgery detected by transcranial Doppler ultrasound. Br J Anaesth 2000;84:629-31.

17. Brown WR, Moody DM, Challa VR, Stump DA, Hammon JW. Longer duration of cardiopulmonary bypass is associated with greater numbers of cerebral microemboli. Stroke 2000;31:707-713.

18. Malheiros SMF, Brucki SMD, Gabbai AA, et al. Neurological outcome in coronary artery surgery with and without cardiopulmonary bypass. Acta Neurol Scand 1995;92:256-260

19. Andrew MJ, Baker RA, Kneebone AC, Knight JL. Neuropsychological dysfunction after minimally invasive direct coronary artery bypass grafting. Ann Thorac Surg 1998;66:1611-1617.

20. Taggart DP, Browne SM, Halligan PW, Wade DT. Is cardiopulmonary bypass still the cause of cognitive dysfunction after cardiac operations? J Thorac Cardiovasc Surg 1999;118:414-421.

21. Crawley F, Stygall J, Lunn S, Harrison M, Brown MM, Newman S Comparison of microembolism detected by transcranial Doppler and neuropsychological sequelae of carotid surgery and percutaneous transluminal angioplasty. Stroke 2000;31:1329-1334. 